\title{
MIR29B2 Pre-miRNA
}

National Cancer Institute

\section{Source}

National Cancer Institute. MIR29B2 Pre-miRNA. NCI Thesaurus. Code C82725.

MIR29B2 pre-miRNA is an oligonucleotide that is encoded by the human MIR29B2 gene and has a role in the regulation of gene expression. 